\title{
The Model of the Five Competitive Forces on Portuguese Electricity Market
}

\author{
Ricardo Raimundo ${ }^{(}$, Nuno Domingues* ${ }^{*}$ \\ ISEC ISEL, Instituto Superior de Educação e Ciências, Instituto Superior de Engenharia de Lisboa, Lisboa, Portugal \\ Email: *nndomingues@gmail.com
}

How to cite this paper: Raimundo, R., \& Domingues, N. (2021). The Model of the Five Competitive Forces on Portuguese Electricity Market. Modern Economy, 12, 140-153.

https://doi.org/10.4236/me.2021.121007

Received: November 17, 2020

Accepted: January 26, 2021

Published: January 29, 2021

Copyright (c) 2021 by author(s) and Scientific Research Publishing Inc. This work is licensed under the Creative Commons Attribution International License (CC BY 4.0).

http://creativecommons.org/licenses/by/4.0/

(c) (i) Open Access

\begin{abstract}
In Portugal, the energy sector apparently shows lack of efficiency as the amount of energy used to generate a unit of GDP, also called energy intensity of the economy (TPES/GDP), an indicator of energy efficiency, which decreased in Portugal in a couple of decades less than in the EU 27 overall. The TPES/GDP indicator stills high in most Portuguese economic sectors in comparison with the EU27 average. To determine the reasons of such lack of energetic efficiency this work aims to analyze the Portuguese electricity market based on the model of the five competitive forces of Michael Porter that was chosen due to the idiosyncrasies of electricity sector, of strategies highly anchored on its external competitive setting and of little innovation around a non-differentiated electricity product of extended life cycle. Firstly, the theoretical aspects of the model are explained; secondly, it is made a critical review, including the reasons for choosing it; thirdly, the model is applied to the electricity market in Portugal and finally the main findings are revealed. The main methodology used is literature review of secondary sources and data. Authors mainly relied on sources of high-quality material. The input data has been collected from national institutes and from the information offered by the main players on their web sites. These sources are certified, and the input information is supported by their credibility and by the supervision departments. Portugal, due to the Country dimension and the barriers, the players are still few, and the electricity market is concentrated. The competition is high among 3 - 4 major players; the barriers are high; the electricity of traditional national suppliers is high although mitigated by the entry of other European Union distributors; the bargaining power of consumers is low and the substitutes are inexistent. Moreover, the equipment in consumption is aggregated to electricity, which is not easy to change. As electricity cannot be differentiated, energy distribution companies need to set strategies to engage consumers. The present paper reflects and analyses on these assumptions and concludes that to augment energetic efficiency, companies in energy markets
\end{abstract}


as Portugal must prioritize diversity, complementary services and non-related products. Also, the low degree of competition has no conditions to be surpassed in the near years due to the inefficient features of the energy market and subsequent barriers.

\section{Keywords}

Liberalization, Privatization, Electricity Market, Porter, Portugal, Energy Market Competition

\section{Introduction}

The amount of energy used to generate a unit of GDP - also called energy intensity of the economy (TPES/GDP) - decreased by 51\% in the EU 27 between 1995 and 2018, although in Portugal it only shrunk by $45 \%$ (Pordata, 2018) ${ }^{1}$, which suggests energy inefficiency comparing to the EU27 mean. The energy intensity of a country's economy is often used as an indicator of energy efficiency, mostly because, at an aggregate level, it is a proxy dimension for the energy required to accomplish energy services across regions. Nevertheless, although Portugal shows high energy intensity, ranking 17th in the EU27 (Pordata, 2018), it does not necessarily have energy inefficiency, as it is a small country of low GDP per capita $\left(24,387.9\right.$ euros $\left.^{2}\right)$. To achieve a coherent picture, other elements should be considered, including energy intensity of distinct economic sectors, the structure of the economy (the share of energy consuming industries), the liberalization degree of the energy sector and the overall climate and weather conditions and geographic features. Portugal has a mild climate of little demand for heating or cooling and it is a small country of equally shorter distances implying lower demand for the transport sector. Also, as we have shown elsewhere (Raimundo \& Domingues, 2020), the electricity market liberalization in Portugal can be classified as moderated. To be precise, although variation in the price to the consumer is one of the highest in Europe, indicating that the market is dynamic, the Herfindahl-Hirschman Index ${ }^{3}$ for households is medium, whereas the ratios of switching distributors are low, meaning customer loyalty.

Nevertheless, Portugal presents the following figures of energy intensity by type of consumer (Pordata, 2018): "agriculture and fisheries" 110.9, "industry" 116.9, and "services" 61.6. Conversely, the EU27 records 130.4, 78.8 and 48.0, respectively, which means that, apart from the primary sector, the country's energetic efficiency is well below the EU with respect to industry and services consumption. Indeed, although energy consumption by type of consumer both used to determine market competitiveness. It is calculated by squaring the market share of each firm competing in a market and then summing the resulting numbers. It can range from zero to 1 and the greater the score the greater the market concentration.
} 
in Portugal and EU27 average counts barely the same with regard to services (Portugal 14.5\% against EU 14.21\%), the Portuguese industry, 28.2\%, and transportation, $36.16 \%$, weigh more in the overall country's energy consumption than the EU27 average, of $25.7 \%$ and $30.5 \%$ respectively (Pordata, 2018). Such weight of industry and transportation in terms of energy consumption, together with the general and sector high energy intensity indicators, suggests a Portuguese inefficient energy/electricity sector. This work intends to carry out a thorough electricity sector analysis that provides insights on the strategic factors behind energy inefficiency.

To carry out such endeavour, Porter's five forces framework seemed a good choice because its model of rivalry competitors, potential new entrants, bargaining power of suppliers and buyers and substitutes relies on the assumption that strategy should be based on the organizational external setting and industry structure (Porter, 1980).

\section{Materials and Methods}

\subsection{Methodology}

This study relies mostly on non-empirical research, in which the researchers adopted both inductive and deductive reasoning to theorize logical assumptions about the Portuguese electricity market, in the light of Porter (1980)'s theory of Five Forces. Building on reflection and personal observation on the field, the researchers carried out this article by gathering relevant data (i.e. statistics) through critical studies, systematic review of literature and meta-analysis on the theme. Therefore, the methodology used is based mainly on qualitative exploration of secondary sources and data. The main sources are pieces of writing on the Porter (1980)'s theory of Five Forces, out of which one will pull out insights, which, in the absence of an adequate amount of quantitative variables, will be exactly classified as "high", "medium" and "low".

\subsection{The Five Forces Model: A Critical Review}

The importance of the Porter analyses is great in defining the strategic direction of a company. Michael Porter (1980) considers market rivalry as an outcome of the five main variables he defined: rivalry level, bargaining power of suppliers and that of customers, the threat of new entrants and of substitutes. These forces are interconnected. They are explained in the diagram of the five competitive forces (Figure 1) (Porter, 1980).

The Level of rivalry between existing companies describes the intensity of competition in a specific industry to take a particular market segment and is set by elements such as diversity, number of competitors and their relative strength, the extent to which industry can be classified as young or mature, high fixed costs, low product differentiation, higher barriers to leave the sector or key strategic constraints in industry. In energy markets, one must add the legislation and the financing dilemmas. 


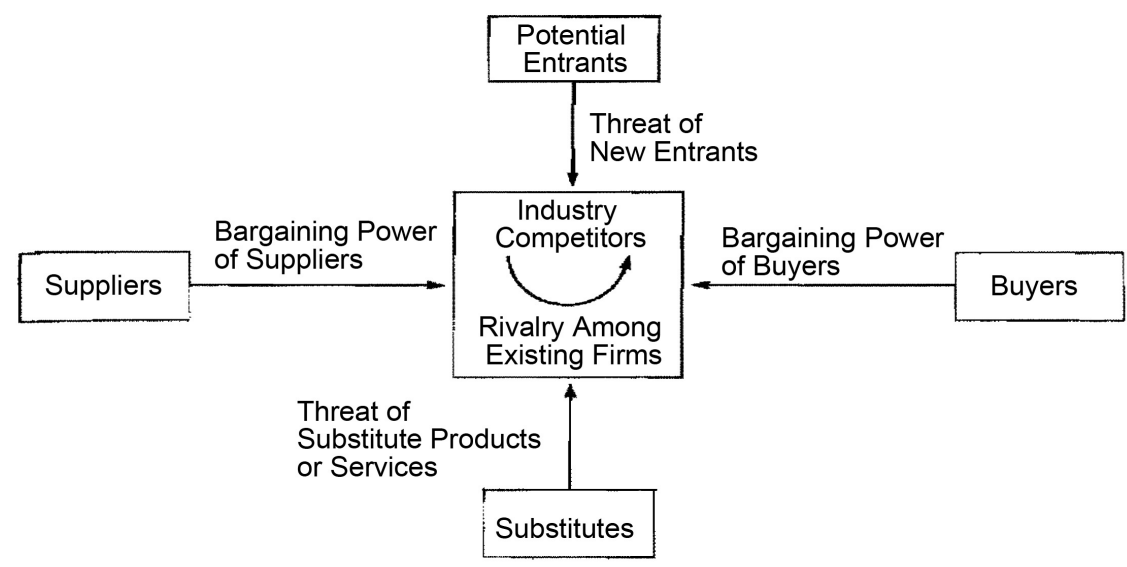

Figure 1. The five competitive forces that determine industry profitability (Porter, 1980).

To be competitive, the company must follow a strategy aimed at two goals: enhancing the employed competitive pressure, growing in size and market share by a strategy of growth, and decrease the supported competitive pressure in differentiating its products from the competitors'. In energy markets, lack of quality is reprimanded by the regulator and the high prices cause that the company is not forwarded, both leading to an hourly non-sell.

Bargaining power of buyers affects an industry by their ability to compel lower prices, negotiate services in terms of quality and quantity, and to define competitors one to another (Porter, 1980). For a firm, buyers could be both the final consumers and companies that distribute products/services throughout given channels. Porter (1980) posits that they could be considered at once both a force and a threat, whether they demand the decreasing of price or demand differentiated products/services and ensuing increased costs. If buyers are a weak force, the companies would increase prices, therefore attaining higher profits. In energy markets in Market Clearing Price (MCP in further text), such as in Portugal, that there is a fixed selling price, the lower revenue is due to the lower MCP. In energy markets in Pay as Bid, the lower revenue is direct since the bid price equals the selling price.

The Bargaining power of suppliers in an industry can be demonstrated through increasing prices or decreasing quality products distributed. Their power depends on several market attributes and importance of the delivering business sector. Power augments if the resource is key for the target company; the number of suppliers is scarce or switching embraces major costs..

The threat of new entrants consists in companies that can compete in an industry. They come up with an aspiration to prevail and frequently present substantial resources. New entrants enter the market in case the profit margin is attractive and the correspondent barriers to entry are weak. Porter (1980) introduced seven potential barriers to entry into a sector: product differentiation, economies of scale, total cost advantages (e.g. due to their access to resources, low cost of designing and position on the curve of experience), transfer costs, the 
required capital, access to distribution channels; and government policy. Product differentiation is based on the intrinsic qualities of products or services, a solid brand identity or quality reputation and reliability (Kotler, 2005). In energy markets, new competitors in production or in distribution were almost not possible. However, legislation allows prosumers, aggregators and brokers that turn upside down this reality. Also, the small-scale energy production and energy decentralization are reinforcing this trend.

Entering a sector demands substantial capital, credibility in finance to obtain loans, investment in technology, facilities and distribution factors that new entrants can attain only by taking risks. In the case, switching, transfer costs that new entrants should support to attract customers already on the market; Uneven access to distribution channels, in ensuring the distribution of the product through distribution channels already controlled by other companies; total cost advantages based on economies of scale for companies already on the market; government policy, by restricting competition while allowing monopolies and constraining regulations. In the case, industries that provide utilities like energy are deemed natural monopolies because it is considered more efficient to have one company that provides electricity in a locality than to allow several companies to compete for the local market. In the meanwhile, the European Commission has worked with member executives to remove most of these constraints.

Substitutes consist in those products of distinct use, from outside the industry, but that can satisfy the same need. Once the threat of substitutes is significant the industry profitability decreases. Substitution products/services restrain the industry potential profit by placing a ceiling on prices. The threat from substitutes is set through elements such as its price and availability, or the product sales price elasticity/sensitivity that varies compared with their substitutes.

Porter's five forces model is therefore a common strategic business technique for industry competition analysis, to evaluate the attractiveness and context influences. Though, as industries features continuously evolve it may be questioned if it is still trustworthy (McGahan, 2000).

First, the nuances of some industries may influence the precision of analysis. Namely, for instance in the case of multiple clusters as seen in peculiar industries that may need to be examined at different segments to implement a coherent analysis, which pose the question of analyzing its multiple segments, as well, to provide a succinct portrait (Johnson, 2009).

Second, the turbulence of industries in terms of change uncertainty, novelty and speediness is deemed as a fundamental reason that may jeopardize the Porter's framework. The fast environmental change may influence heavily both the context and the response of firms' capabilities. Specifically as in the case of merging of previously distinct industries, which may include also technological innovation, able to boost new products and increase ensuing competition (Malhotra \& Gupta, 2001).

Third, the nature and intensity of industry competition may be changed by combining products/services in order that they balance one to another, adding 
new competitive forces within an industry, ending up for example cooperating rather than competing to each other (Burton, 1995). Likewise, complementary products extend important business opportunities for firms for cooperating rather than competing with each other as the model posits (Van den Berghe et al., 2000), which could inclusive be considered as an added sixth competitive force with noteworthy profit potential and competition insight (Brandenburger, 1995; Yoffie \& Nalebuff, 2006).

To summarize, the debate hitherto has assumed that the five forces framework is able to deal with the core competition forces within an industry, while some other issues may be considered as well in order attain greater accurateness. Despite being a critical strategy tool, which can provide useful insights into all organizations, the five forces framework, may be impaired by industry-specific profit circumstances that may push the model to further developments (Christensen, 2001). Likewise, the framework can always be improved, as it can be applied into the modern business context, adding for instance factors such as the rating the impact of forces, assigning them a weight to explore how they interplay and create industry patterns (Grundy, 2006).

Hence, an effort to improve the use of the framework in today's contexts such as the energy sector should guarantee that it includes its current characteristics into the study (Grundy, 2006). One should take into account the influence of other issues than the Porter's framework, related with marketing innovation or internet (Karagiannopoulos et al., 2005) and ensuing profit capabilities of some predominant players (Siaw \& Yu, 2004).

The core of the framework appeared adequate for the idiosyncrasies of the Portuguese energy sector due to the following reasons:

- First, the Portuguese energy sector, although increasingly liberalized, is still one of the most regulated because of its strategic national interest. Thus, government policies and macroeconomic conditions heavily impact the five sector forces that in turn will shape organizational strategies.

- Second, despite being liberalized, the Portuguese energy retailing sector is still moderately concentrated around 4 - 5 major players, large organizations of capital hierarchical concentration, which, in sum, support the five forces framework, heavily centred on large, established companies (Aktouf, 2005). Indeed, in line with Porter's framework, the Portuguese energy sector resembles a classic market, of a rather static and mass market structure, made up of large organizations of few or nonstrategic alliances and innovativeness (Indiatsy et al., 2014).

- Third, the strategies of this energy sector increasingly shift towards customers, in terms of marketing campaigns with little or none price disparity. Thus, it is worthwhile to apply Porter's framework both to ascertain the marketing campaigns and bargaining power of costumers, understanding of how profit is distributed between the five forces. Furthermore, the Porter's model favours corporations that produce and distribute through scale, undifferentiated products and services, in which each additional product (e.g. electron) 
or service adds equal profit (Bruijl, 2018).

- Fourth, the core framework is not specifically designed for "innovation" and "change". The model does not emphasize strategic thinking in terms of shaping the future or creating long-term value using innovative ways; instead, it over enhances the existing competitive environment through an "outside-in" standpoint (Bruijl, 2018). In the case, the companies operating within the energy competitive market hardly step out of their current context of an extended product life cycle.

- Finally, although the five forces model has been extensively applied to varying sectors of activity, it is almost absent regarding energy matters. We could only find three articles out of 193 overall on the topic through a detailed search of Scopus journals in the last 30 years, namely, Hou et al. (2020) with a study on the competitiveness of energy resources with respect to the integration of distributed energy resources in China with blockchain technology, which, according to authors, allows to break the centralization of energy pipeline; Gill (2016) with a paper on the business strategy of an energy company, in the light of the five forces model and competitive positioning analysis, which concludes for the need for customer and competitive focus in energy markets; and Dar (1995), with a piece of writing on the influence of the Porter's Five Forces both on the electricity industry and on its management executives.

Due to the issues discussed above, it is therefore opportune to analyze the Portuguese electricity market in the light of the Porter's Five Forces framework.

\section{Results and Discussion: The Portuguese Electricity Market}

\subsection{Threat by New Entrants}

The electrical power industry does not concede simple access. It demands considerable investment for building plants, keeping equipment, environmental requirements and research and development (R\&D). It is also likely for companies within the industry to refrain access by generating electricity efficiently. For example, some companies such as Endesa (2020) or Iberdrola may use renewable resources (e.g. wind) to produce electricity in a manner that is more cost effective. This can often result in a competitive edge on pricing: $0.1494 € / \mathrm{kWh}$ (ERSE, 2020). Iberdrola uses $100 \%$ renewable energy (ERSE, 2020). Iberdrola uses $100 \%$ renewable energy. The threat of new entrants is therefore low due to:

- High fixed costs, high regulation and medium market maturity that constitute considerable barriers for new entrants.

Nonetheless, the product is undifferentiated (e.g. electron) and the switching costs for the end-user are low, which constitutes an opportunity for new entrants.

\subsection{Substitute Products and Services}

There are different cost-effective ways that can be used to produce electricity. 
These approaches are widely deemed as non-renewable and renewable. Coal is a non-renewable method and is one of the most broadly used resources in the electricity industry. Notwithstanding, companies are stressing renewable ways to produce electricity. Some of these modes comprise solar, hydro, wind and bio-fuel, whereas nuclear methods are non-existent in Portugal so far Coal availability is limited and therefore electricity from nuclear, hydro and other renewable sources could be used as substitute for thermal electricity in future. "Wind and solar methods are now cheapest across more than two-thirds of the world and by 2030 they erode commissioned coal and gas in everywhere" (Bloomberg NEF, 2019). In short, the threat of substitutes is low due to low switching costs (the cost of switching to substitutes like gas, solar, etc.).

\subsection{Rivalry among Industry Participants}

The rivalry among existing companies is high due to:

- Competitor size and number-there are only five major players that are large in size;

- It is hard to exit the sector due to its fixed costs;

- It is a sector hard to grow due to the high investment involved;

- Players are service oriented rather than just product oriented;

- The positioning is centred on the customer need rather than just in the product, which augments the switching cost for customers.

In this way, there is fierce competition among the electricity companies that hardly differentiate at price level. In Portugal, the Electricity Price and Energy Price comprehend distinct issues. The electricity price defines the amount the customer will pay per day, depending on the contracted electricity. In turn, the energy price, defines the price that the customer will pay depending on the energy consumption in $\mathrm{kWh}$. These added prices work out the final price. Moreover, the contracted electricity represents the maximum power charge supported by the consumers' installation. The greater the contracted electricity, the more electrical equipment you can keep connected simultaneously.

Those prices are defined by Entidade Reguladora dos Serviços Energéticos (Regulatory Entity for Energy Services-ERSE in further text) and revised annually (2019 Rates). Likewise, the demand for energy is analysed annually by ERSE that accounts the correspondent report (2019 Rates). The yearly tariff is worked out based upon the evolution of primary energy prices, energy demand, investments in new plants, the consumer price index, etc. Also, the tariff is set by activity in which those items weigh differently for the final price. The tariffs are defined by additivity regarding each deverticalization area and speciality (Aktouf, 2005). The most frequent contracted electricity for the residential sector are between $3.45 \mathrm{kVA}$ and $6.90 \mathrm{kVA}$. The major competitors in Portugal are Goldenergy, GALP, EDP, Iberdrola, Endesa (2020), which positioning are the following:

\section{1) GoldEnergy}

This competitor (Goldenergy, 2020) adopts a low-cost strategy to gain market 
share. The company hardly offers extra services, except some packages with AutomóvelClube de Portugal (Automobile Club of Portugal) and Loja do Condomínio (condominium entity). The prices of the MaisCustomere19 (PlusCustomer19) campaign with direct debit and electronic invoice, which are applied for dual contracts (electricity and gas) are shown (Table 1).

2) GALP

This competitor, a group of Portuguese companies in the energy sector, employs simple and bi-hourly tariffs up to $20.7 \mathrm{kVA}$ for electricity and consumption up to $10,000 \mathrm{~m}^{3} /$ year for natural gas for private customers who use electricity for domestic purposes. Different service packages require membership for example of "GalpAssistência Casa" or "GalpAssistência Família for the Galp + plan", "GalpFatura de Volta plan" or "Continente plan". Therefore, it adopts a differentiation strategy of highest prices based on its services and products. This rival entered the electricity market in order not to lose its share of related businesses of natural gas for domestic uses and diesel/gasoline in mobility. Thus, the company keep up with the change with respect to primary energy choice by consumers (Table 2).

3) EDP

This competitor, Electricidade de Portugal (Electricity of Portugal ${ }^{4}$ ), is leader with respect to Dual Contracts (electricity plus gas). It presents the greatest assortment of products and services ${ }^{5}$ and positions on a close engagement with customers through the EDP community ${ }^{6}$. offering for example 1 Euro per month in case of an existing customer recommends a new one. Regarding gas, the prices are the following (Table 3 ).

Still, when it comes to electricity tariffs, are the following (Table 4).

Table 1. GoldEnergy tariffs.

\begin{tabular}{ccc}
\hline \multicolumn{2}{c}{ MaisCustomere 19 campaign with direct debit and electronic invoice } \\
\hline Contracted Electricity & $\begin{array}{c}\text { Contracted Electricity }(€ / \text { day }) \\
0.3054\end{array}$ & $\begin{array}{c}\text { Simple Consumption } \\
(€ / \mathrm{kWh})\end{array}$ \\
\hline $5.75 \mathrm{kVa}$ & $\begin{array}{c}\text { Fixed Term }+ \text { Network Access } \\
(€ / \text { day })\end{array}$ & Consumption $(€ / \mathrm{kWh})$ \\
Echelon & Exempt +0.0065 & 0.0657 \\
\hline
\end{tabular}

Table 2. GALP tariff.

\begin{tabular}{ccc}
\hline Contracted Electricity & $\begin{array}{c}\text { Contracted Electricity }(€ / \text { day }) \\
\text { Simple Consumption } \\
(€ / \mathrm{kWh})\end{array}$ & $\begin{array}{c}0.3206 \\
\text { Echelon }\end{array}$ \\
Echelon 1 & $\begin{array}{c}\text { Fixed Term }+ \text { Network Access } \\
(€ / \text { day })\end{array}$ & Consumption $(€ / \mathrm{kWh})$ \\
0.0687 & 0.0645 \\
\hline
\end{tabular}

${ }^{4}$ https://www.edp.pt/particulares/energia/gas-eletricidade/

${ }^{5}$ https://www.edp.pt/particulares/

${ }^{6}$ https://www.edp.pt/particulares/planeta-zero/ 
Table 3. EDP gas tariff.

\begin{tabular}{cccc}
\hline & Price EDP & Discount & Discounted Price \\
\hline Electricity $(€ /$ day $)$ & 0.3283 & $2 \%$ & 0.3217 \\
$\begin{array}{c}\text { Energy }(€ / \mathrm{kWh}) \\
\text { Normal }\end{array}$ & 0.1546 & $2 \%$ & 0.1515 \\
\hline
\end{tabular}

Table 4. EDP electricity tariff.

\begin{tabular}{cccc}
\hline & Price EDP & Discount & Discounted Price \\
\hline Fixed tariff term $(€ /$ day $)$ & 0.0688 & $5 \%$ & 0.0654 \\
Energy $(€ / \mathrm{kWh})$ & 0.0641 & $5 \%$ & 0.0609 \\
\hline
\end{tabular}

\section{4) Iberdrola}

This competitor, a Spanish company, stands out for having 100\% renewable energy. It presents two types of contracts, which are "Casa Iberdrola" (an energy base plan) and "ProteçãoEléctricaLar" (Electric Home Protection), with added complimentary services. This player, along with Endesa (2020), aims at gaining market share by internationalizing in partnership with EDP, particularly in renewable EDP investments and overseas in former colonies and cultural near markets such Brazil, Angola, Cape Verde and Mozambique. China has been also a possibility. Collaborating with competitors builds scale and contribute to increase the market size rather than just competing for domestic market. It exhibits the following prices (Table 5).

5) Endesa

This player, also a Spanish company, aims at internationalizing, as well as Iberdrola. Nevertheless, it shows a less bold strategy in terms of low prices and ensuing exposure. Its positioning comprises in turn a free month offer to new customers in addition to four different price options: ElectricityPack Rate, Single Rate, Simple E-Light Rate and Bi-hourly E-Light Rate. Also, it presents two service packages: "OK Electrodomésticos" and "OK Serviços" (OK household appliances and OKServices) (Endesa, 2020). Finally, the company also mounted a club pretty like the "EDP Community", highlighting the booking procedure. The prices employed are the following (Table 6).

To note that in Portugal there are the so called "Comercializadores de ÚltimoRecurso", CUR in further text that due to its small representativeness were not included in the present study. These are minor competitors, redundant traders, companies with licence to supply electricity and/or natural gas, applying tariffs defined by the Regulatory Entity (EntidadeReguladora dos ServiçosEnergéticos-ERSE) in specific cases where major players cannot operate at first. The CUR (The list of electricity CUR) can supply electricity and/or natural gas to: final consumers with active contracts, as long as the tariffs legally provided for by ERSE are applicable; economically vulnerable consumers (individuals of low income); consumers whose market trader has been prevented from commercialize energy; and consumers located where there is no fair offer by electricity 
Table 5. Iberdrola tariff.

\begin{tabular}{ccc}
\hline Contracted Electricity & Contracted Electricity $(€ /$ day $)$ & Simple Consumption $(€ / \mathrm{kWh})$ \\
\hline $5.75 \mathrm{kVa}$ & 0.2621 & 0.1494 \\
Echelon & Fixed Term + Network Access & Consumption $(€ / \mathrm{kWh})$ \\
Echelon 1 & $(€ /$ day $)$ & 0.0549 \\
\hline
\end{tabular}

Table 6. Endesa tariff.

\begin{tabular}{ccc}
\hline Contracted Electricity & Contracted Electricity $(€ /$ day $)$ & Simple Consumption $(€ / \mathrm{kWh})$ \\
\hline $5.75 \mathrm{kVa}$ & 0.28 & 0.1495 \\
Echelon & Fixed Term + Network Access & Consumption $(€ / \mathrm{kWh})$ \\
Echelon 1 & $(€ /$ day $)$ & 0.058 \\
\hline
\end{tabular}

or natural gas traders.

\subsection{Bargaining Power of Suppliers}

Because the electricity industry requires a considerable amount of capital investment, the number of suppliers in this industry face many barriers to entry. It can be considered that the supplier power is high due to:

- Supplier size-large, resourceful companies;

- Oligopoly threat-Small number of suppliers (five companies);

- Switching costs-High, as very demanding in terms of economic structure;

- Few substitute inputs;

- Medium player dispensability-five major players;

- Differentiated input-companies can choose electricity in case of company buying electricity from wholesale market and selling to the end-users, and coal or gas in case the company is in power generation plant.

\subsection{Bargaining Power of Buyers}

Buyers in the electricity industry include commercial and non-commercial customers. Those players provide electricity to the whole country accounting for nearly 10 million customers (INE, 2018). Companies such as for example Goldenergy strive to supply electricity at low rates to augment their consumption rates and to promote their products combined with other related products (e.g. gas) (ERSE). It can be assumed that, overall, the buyer has low power in terms of:

- Medium Switching Cost-switching cost for the buyers is low as there are various players with barely the same fares for a not differentiable product-electricity;

- Buyer size is in average pretty small-the majority of residential market;

- A moderate risk of oligopoly threat-five players;

- Little price sensitivity/elasticity as prices hardly vary; 
- Economic power of electricity providers;

- Low product dispensability;

- Industrial consumers have huge demand for electricity.

\section{Conclusion}

The Portuguese electricity sector exhibits active and competitive markets with considerable number of private participants, in which the government controls only partly the distribution. The barriers to enter the sector are high due to the investment and regulation involved. Because of sector concentration upon 5 major players, their bargaining power is high and as the substitutes are virtually inexistent, in the end, the bargaining power of buyers is low, contributing therefore to loss of efficiency.

Also, new products/services come up whereas customers often seek discounts and offerings on established products/services, also limiting their bargaining power. New services contribute to reduce the abandonment of loyal customers to other competitors.

The Portuguese electricity sector exhibits low margins and very similar prices among competitors that in average present values for the $5.75 \mathrm{kVa}$ contracted electricity of $€ 0.30 /$ day and for simple consumption of $€ 0.15 / \mathrm{kWh}$. The differentiation comes up mostly through sporadic marketing campaigns offering minor discounts and distinct marketing packages. In short, the efforts for continually seek for alternative ways to stay ahead of rivals are principally at marketing level, by slight changes in product delivery and combinations (electricity and gas) rather than by a deep strategic differentiation, which ends up contributing for the poor energetic efficiency ratio (TPES/GDP).

Furthermore, the distribution companies have low degree of innovation since the product is equal and cannot be differentiated. Thereby, electricity companies in energy markets as Portugal must prioritize diversity, complementary services and non-related products, aiming at ameliorating the general energetic efficiency ratio (TPES/GDP).

\section{Conflicts of Interest}

The authors declare no conflicts of interest regarding the publication of this paper.

\section{References}

Aktouf, O. (2005). The False Expectations of Michael Porter's Strategic Management Framework. Revista Gestão e Planejamento, 6, 75-94.

Brandenburger, A., \& Nalebuff, B. (1995). The Right Game: Use Game Theory to Shape Strategy. Harvard Business Review, 73, 57-71.

Bruijl, G. (2018). The Relevance of Porter's Five Forces in Today's Innovative and Changing Business Environment. https://doi.org/10.2139/ssrn.3192207

Burton, J. (1995). Composite Strategy: The Combination of Collaboration and Competi- 
tion. Journal of General Management, 21, 1-23.

https://doi.org/10.1177/030630709502100101

Christensen, C. (2001). The Past and Future of Competitive Advantage. Sloan Management Review, 42, 105-109.

Dar, V. K. (1995). The Future of the U.S. Electric Utility Industry. The Electricity Journal, 8, 16-25. https://doi.org/10.1016/1040-6190(95)90057-8

Endesa (2020) Tarifa E-luz e E-Gás Plans.

https://desconto-endesa.pt/?tsource=ggl-srch_ggl_ENDESA_CPC_\&campaignid=1391 743639\&adgroup $=59623413796 \&$ targetid $=\mathrm{kwd}-445366540717$ \&keyword=\%2Bendesa \& mat-

chtype $=\mathrm{e} \&$ network $=\mathrm{g} \&$ device $=\mathrm{c} \&$ creative $=330136865507 \&$ adposition $=1 \mathrm{t} 1$ \&utm_sourc $\underline{\text { e=google\&utm_medium }=\text { search\&utm_campaign=MARCA\&gclid=Cj0KCQjwvo_qBR }}$ DQARIsAE-bsH9kTvYtgxYnqRWrjKwNZCuax403Mf4uc6T0jAj240E0DLJCYKGOeo0aAsXK EALw_wcB

ERSE (2020). The List of Electricity CUR.

https://www.erse.pt/gas-natural/funcionamento/comercializacao/

Gill, A. (2016). Floundering in a Deregulated Market: An Energy Company Seeks New Strategies. Journal of Business Strategy, 37, 27-35. https://doi.org/10.1108/JBS-08-2014-0101

Goldenergy (2020). Preços de referênciaTarifário + Cliente. https://goldenergy.pt/servicos/precos-de-referencia/

Grundy, T. (2006). Rethinking and Reinventing Michael Porter's Five Forces Model. Strategic Change, 15, 213-229. https://doi.org/10.1002/jsc.764

Hou, J.C, Wang, C., \& Luo, S. (2020). How to Improve the Competiveness of Distributed Energy Resources in China with Blockchain Technology, Technological Forecasting and Social Change. Technological Forecasting and Social Change, 151, Article ID: 119744. https://doi.org/10.1016/j.techfore.2019.119744

Indiatsy, C., Stephen Mwangi, M., Nyamboga Mandere, E., Bichanga, J., \& George, G. E. (2014). The Application of Porter's Five Forces Model on Organization Performance: A Case of Cooperative Bank of Kenya Ltd. European Journal of Business and Management, 6, 75-85.

Instituto Nacional de Estadística (2018). Resultados da Pesquisa. https://www.ine.pt/xportal/xmain?xpid=INE\&xpgid=ine_pesquisa\&frm_accao=PESQ UISAR\&frm_show_page_num=1\&frm_modo_pesquisa=PESQUISA_SIMPLES\&frm_t exto=Anuário+estatístico+da+região\&frm_modo_texto=MODO_TEXTO_ALL\&frm_dat a_ini $=\&$ frm_data_fim $=\&$ frm_tem $\& x l a n g=p t$

Johnson, G., Scholes, K., \& Whittington, R. (2009). Fundamentals of Strategy. Essex: Pearson.

Karagiannopoulos, G. D., Georgopoulos, N., \& Nikolopoulos, K. (2005). Fathoming Porter's Five Forces Model in the Internet Era. Info, 7, 66-76. https://doi.org/10.1108/14636690510628328

Kotler, P. (2005). The Role Played by the Broadening of Marketing Movement in the History of Marketing Thought. Journal of Public Policy and Marketing, 24, 114-116 https://doi.org/10.1509/jppm.24.1.114.63903

Malhotra, A., \& Gupta, A. (2001). An Investigation of Firms' Responses to Industry Convergence. Academy of Management Proceedings, 2001, G1-G6. 
https://doi.org/10.5465/apbpp.2001.6123186

McGahan, A. (2000). How Industries Evolve. Business Strategy Review, 11, 1-16.

Pordata (2018). https://www.pordata.pt/Homepage.aspx

Porter, M. (1980). Competitive Strategy. New York, NY: The Free Press.

Raimundo, R., \& Domingues, N. (2020). Evaluation of the Electricity Liberalization Impact on Households and Retail Consumers. In IEEE International Conference on Environment and Electrical Engineering.

Siaw, I., \& Yu, A. (2004). An Analysis of the Internet in the Banking Industry, using Porter's Five Forces Model. International Journal of Management, 21, 514-523.

The 2019 Rates.

http://www.erse.pt/pt/electricidade/tarifaseprecos/2019/Documents/Tarifas $\% 20 \mathrm{e} \% 20 \mathrm{Pr}$ e\%C3\%A7os\%202019.pdf

Van den Berghe, L., \& Verweire, K. (2000). Convergence in the Financial Services Industry. Geneva Papers on Risk and Insurance, 25, 262-272.

Yoffie, D., \& Kwak, M. (2006). With Friends Like These. Harvard Business Review, 84, $88-98$. 